\title{
The effects of obesity and mobility disability in access to breast and cervical cancer screening in France: results from the National Health and Disability Survey
}

\author{
Clémence Bussière, Jonathan Sicsic, Nathalie Pelletier-Fleury*
}

From Health Services Research: Evidence-based practice

London, UK. 1-3 July 2014

\section{Objectives}

We aimed to disentangle the effects of obesity and mobility limitation on cervical and breast cancer screening among community dwelling women.

\section{Methods}

The data source was the French national Health and Disability Survey - Household Section, 2008. The Body Mass Index (BMI) was used to categorize obesity status. We constructed a continuous score of mobility limitations to assess the severity of disability (Cronbach's alpha $=0.84)$. Logistic regressions were performed to examine the association between obesity, mobility limitations and the use of Pap test $(n=8$ 133) and the use of mammography ( $\mathrm{n}=7$ 561). Adjusted odds ratios were calculated (AOR).

Interaction terms between obesity and the disability score were included in models testing for effect modifications.

\section{Results}

Compared with non-obese women, the odds of having a Pap test in the past 3 years was $24 \%$ lower in obese women $(\mathrm{AOR}=0.76 ; 95 \% \mathrm{CI}: 0.65$ to 0.89$)$, the odds of having a mammogram in the past 2 years was $23 \%$ lower (AOR $=0.77 ; 95 \%$ CI: 0.66 to 0.91 ). Each time the disability score was 5 points higher, the odds of having a Pap test decreases by $20 \%$ (AOR $=0.96$; $95 \%$ CI: 0.94 to 0.98 ), the odds of having a mammogram decreases by $25 \%$ (AOR $=0.95$; 95\% CI: 0.94 to 0.97 ). There was no significant interaction between obesity and disability score.

\section{Conclusion}

Obesity and mobility limitation are independently associated with a lower likelihood of cervical and breast cancer screening. Protective outreach and follow-up are necessary to reduce inequalities and thus to reduce health disparities in these vulnerable and high-risk populations of obese women with disabilities.

Published: 7 July 2014

doi:10.1186/1472-6963-14-S2-P13

Cite this article as: Bussière et al:: The effects of obesity and mobility disability in access to breast and cervical cancer screening in France: results from the National Health and Disability Survey. BMC Health Services Research 2014 14(Suppl 2):P13.
Submit your next manuscript to BioMed Central and take full advantage of:

- Convenient online submission

- Thorough peer review

- No space constraints or color figure charges

- Immediate publication on acceptance

- Inclusion in PubMed, CAS, Scopus and Google Scholar

- Research which is freely available for redistribution 